pointed, one to present a Report on the scientific aspect of the question, the other to visit some of the chief libraries and ascertain to what extent the asserted deterioration of leathers is a fact. This Committee has already visited the British Museum and the private library of Mr. Huth, soon, alas! to disappear from London.

The mention of this Committee on Leathers reminds us of a very pretty booklet which has recently appeared : 'A Catalogue of Books bound by S. T. Prideaux between 1890 and 1900, with twenty-six illustrations.' Miss Prideaux is herself the publisher, and the colophon of her book states that 'This Catalogue was printed by S. T. Prideaux and K. Adams in the Spring of 1900 at 37, Norfolk Square.' Type, press-work, and the arrangement of the page are all admirable, and the twenty-six illustrations will certainly help to raise Miss Prideaux' already high position among artistic bookbinders. Her work is always precise and well laid out, and some of the covers here figured, notably Plate I4 ('Love in Idleness') and Plate 24 ('Child Christopher'), show an unusual grace and lightness of touch.

For the notice which follows these 'notes' readers are indebted to Mr. Weale. The series is one which certainly deserves all possible success.

A. W. Pollard.

\title{
CRITICAL BIBLIOGRAPHIES.
}

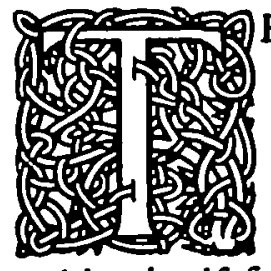

HE 'Société des Etudes Historiques' of Paris has undertaken the publication of a series of critical bibliographies. Four of these, as also an Introduction by Mr. F. Funck-Brentano, have already appeared. They will, I think, meet a want which is making itself felt more and more every year. This pro- 
gressive nineteenth century has seen a marvellous change in the facilities afforded to authors for the production of their works; we easily recognize the great advantage arising therefrom; much that is of value is thus preserved for posterity which, under the adverse circumstances of a former age, would needs have been left unprinted; but there is also this drawback, that a good deal of rubbish sees the light, and in a busy age like the present it is a great boon to have some means of distinguishing the good from the bad. The number of works now published is enormous, and is ever on the increase. In $181 \mathrm{I}$ the National Library at Paris added but 2,000 books to its store, while now it is yearly increased by over 60,000 volumes. In 1898 over 100,000 were acquired by the Library of the British Museum. The 'Académie des Sciences' of Paris prints annually about 5,000 memoirs, articles, and notices. There are some 6,000 societies in the world which publish memoirs, and it has been calculated that these amount together to an annual total of 600,000 . If we turn to bibliographies of any particular subject we may well be amazed at the revelation thereby afforded. Mr. Stein's catalogue of publications on Joan of Arc enumerates over 12,000, while M. Paul Otlet mentions a specialist who has gathered together over 3,000 books and articles on one particular disease of the eyes. In both general catalogues and special bibliographies the title of each book, no matter how good or how worthless, is inscribed alike. The student wishing to read up any subject is simply bewildered at the mass of literature of the existence of which these inform him without affording any indication as to which are the best works and articles relative thereto. Now this is precisely what the new series is intended to do.

The Society will intrust the bibliographies to specialists, and they will be issued as separate pamphlets, which can be classed in whatever manner may appear most convenient to the purchaser. The lines laid down by the 
Society are not too rigid; owing to the diversity of subjects, each bibliographer will be allowed a good deal of liberty, provided that he confines himself to mentioning only such books and articles as are useful or interesting to consult, with brief critical notes on the merits, defects, and character of the principal works. As the undertaking is an international one, the authors will be left free to draw up the bibliographies intrusted to them in the language they prefer. This is only reasonable, for anyone wishing to study the literature or the constitution of any particular country must necessarily know the language of that country; a bibliography, therefore, of works on the History of Paris should be in French; on the reign of Henry VIII., in English; on German poetry, in German. The size of each bibliography will vary considerably, according to the importance of the subject; thus, of those issued, that on Bossuet fills thirty-one pages, that on F. Schubert only seven; whilst some of those in preparation, such as the Reign of Louis XIV., Greek and Latin Numismatics, Education in Great Britain and her Colonies, will certainly require a much larger number.

It is an everyday occurrence to meet with books and articles quoting as authorities works containing errors which have been long ago refuted in articles or reviews of the existence of which the writer was not cognizant. If this series succeeds, such oversights will become inexcusable.

W. H. James Weale. 